\title{
El darwinismo social y la filología decimonónica: rastreo de la ideología a través de la prensa histórica
}

\author{
Juan Carlos Tordera Yllescas ${ }^{1}$ \\ Universitat de València-Grupo GIEL, España
}

\begin{abstract}
Resumen
En este trabajo, se persigue demostrar que el pensamiento darwiniano estaba enraizado en concepciones supremacistas y que este pensamiento no solo marcó la biología decimonónica, sino también el resto de disciplinas sociales y humanas al convertirse la biología como máximo exponente de lo que se entendía como ciencia. No solo se tomaron como premisas los presupuestos metodológicos de la biología, sino también su concepción supremacista. Y la filología no fue una excepción. A través del rastreo en la prensa histórica decimonónica, queremos demostrar que estas ideas calaron en la sociedad, pero también en el pensamiento filológico hispánico del siglo XIX. La reconstrucción de la pretendida lengua indoeuropea o lengua aria estaba ligada a la reconstrucción de una cultura más evolucionada y moralmente mejor que el resto de sociedades/ culturas. De esta manera, el supremacismo racial halló un sustento pretendidamente científico para unos valores totalmente aberrantes. La filología hispánica del XIX fue cómplice en este proceso.
\end{abstract}

\footnotetext{
1 Para correspondencia, dirigirse a: Juan Carlos Tordera Yllescas (juan.tordera@uv.es),
} Facultat de Magisteri, Avda. Tarongers, 4. 46022, Valencia. ORCID 0000-0002-6297-4180. 
Palabras clave: Biología darwinista, supremacismo, filología decimonónica, prensa.

\section{Social Darwinism and nineteenth-Century Philology: TRACING THE IDEOLOGY THROUGH THE HISTORICAL PRESS}

Abstract

This work seeks to demonstrate that Darwinian thought found its origins in supremacist conceptions and that this thought not only marked nineteenth-century Biology, but also the rest of social and human disciplines, because Biology was the maximum exponent of what was understood as science. Not only the methodological presuppositions of Biology were taken as premises, but also its supremacist conception. And Philology was no exception. Through the search in the nineteenth-century historical press, we want to show that these ideas influenced society, but also Hispanic philological thought in the nineteenth century. The reconstruction of the alleged Indo-European language or Aryan language was linked to the reconstruction of a more evolved and morally better culture than the rest of societies/cultures. In this way, racial supremacism found a supposedly scientific basis for totally aberrant values. The Hispanic Philology of the XIX century was also an accomplice in this process.

Keywords: Darwinian Biology, supremacism, 19th century Philology, press.

Recibido: 08/12/20 Aceptado: 10/02/21

\section{INTRODUCCIÓN ${ }^{2}$}

En el siglo XIX, las diferentes disciplinas florecientes que nacieron o se desarrollaron por entonces presentaron, lejos de la objetividad pretendida por el paradigma científico actual, un sesgo racial y supremacista que impregnó todo su pensamiento. La biología es un caso paradigmático de este sesgo:

2 Este trabajo se ha realizado en el marco del proyecto LinPePrensa. Ideas lingüisticas y pedagógicas en la prensa española del siglo XIX, concedido por el Ministerio de Ciencia, Innovación y Universidades del Gobierno de España (ref. PGC2018-098509-B-I00). 
con la obra de Charles Darwin, no solo se inicia la biología "científica", sino que se proporciona una justificación teórica, seudocientífica, para los planteamientos raciales de la época. Y, al igual que la biología, otras disciplinas humanísticas o sociales siguieron sus pasos, como ocurrió con la antropología o la psicología.

Dentro de este contexto histórico de las ciencias, la filología no fue una excepción a la norma. La filología también fue cómplice de sustentar este paradigma seudocientífico al tratar de identificar lenguas o culturas (términos casi usados de manera sinonímica o, al menos, fácilmente intercambiables) superiores e inferiores a través de unas características inherentes o consustanciales que determinaban dicha separación, pero cuya justificación difícilmente resistirían un análisis crítico. Su intento por establecer una lengua/cultura aria, superior espiritualmente a cualquier otra lengua, es un buen ejemplo de esta afirmación. Es el momento en el que se impone la idea herderiana del Volksgeist y en el que se asume la identidad entre una lengua, una cultura, una raza y una nación.

Hasta hace poco, ni los principales manuales de lingüística con diversa tradición lingüística (Alonso-Cortés 2002; Coseriu 1986; Hualde, Olarrea, Escobar, Travis y Sanz 2020; Malmberg 1982; Martín Vide 1996; Moreno Cabrera 1997 y 2000; Newmeyer 1990) ni siquiera los de historia de la lingüística (Arens 1976; Černý 1998; Marcos Marín 1994; Robins 2000) han prestado un especial interés por estos aspectos externos, por lo que estos hechos tendían a ser tratados de soslayo, cuando no ignorados, aunque el racismo de la filología decimonónica pueda ser un hecho bien conocido. En la actualidad, esta perspectiva ha de ser revisada cambiando y entendemos que se debe prestar más atención a los aspectos ideológicos de la filología. Dentro de este marco conceptual, presentamos este trabajo. Nuestro objetivo es mostrar cómo los aspectos ideológicos impregnaron el pensamiento filológico hispánico de la segunda mitad del siglo XIX. Con la finalidad de cumplir con este objetivo, se realiza un rastreo en la prensa histórica de este período, siguiendo la metodología de otros trabajos (proyecto "Ideas lingüísticas y pedagógicas en la prensa española del siglo XIX (LinPePrensa)"). En este sentido, se seleccionan y se analizan críticamente diferentes muestras de la prensa histórica que pongan de relieve el sesgo ideológico del pensamiento filológico del momento, pensamiento que estuvo vigente, cuando menos, hasta el nacimiento de la obra póstuma de Ferdinand de Saussure. 


\section{LA IDEOLOGÍA DECIMONÓNICA EN LAS DISCIPLINAS CIENTÍFICAS}

\subsection{EL CONTEXTO IDEOLÓGICO DE LAS CIENCIAS DECIMONÓNICAS}

Como ya se ha defendido en Tordera Yllescas (2017), el siglo XIX es un contexto en el que el supremacismo y el racismo impregnan la ideología del momento. Bien es cierto que este tipo de ideología no es un hecho novedoso frente a los siglos anteriores (Harris 2007 [1968]: 82-86), pero lo que sí es inédito es el hecho de que esta ideología tenga un sustento pretendidamente "científico". Se trata de naturalizar los valores racistas, de tal manera que el deber-ser racista de la época se confunde con el ser. La axiología segregacionista se convierte en conocimiento científico.

Es un hecho paradigmático que la biología nazca influenciada por el racismo social decimonónico: en 1859, Charles Darwin publicó su trabajo conocido bajo el título Origen de las especies, obra que da el pistoletazo de salida de la biología científica y, en 1871, se publica El origen del hombre, obra en la que se desarrollan las tesis darwinistas aplicadas al estudio de la evolución del hombre. En esta última obra, se puede observar cómo la ideología racista impregna buena parte del pensamiento darwinista: se defiende que la raza negra es evolutivamente inferior y esta raza es juzgada como embustera, inmoral, incivilizada... Para el padre de la biología, la raza negra era el eslabón más cercano evolutivamente al mono y, en concreto, al gorila (Darwin 1972 [1871]: 150), pues Darwin asumió erróneamente que el pariente antropomorfo más cercano era el gorila y no el pan troglodytes (chimpancé). Asimismo, en dicha obra, se asume la superioridad religiosa (Darwin 1972 [1871]: 92-93), moral (Darwin 1972 [1871]: 64-65), estética (Darwin 1972 [1871]: 91), y, por supuesto, intelectual (Darwin 1972 [1871]: 123-124) de la sociedad europea o "raza" blanca frente al resto de civilizaciones o razas (términos utilizados de manera indistintas), a las que tacha de sociedades/razas inferiores e incluso semihumanas (Darwin 1972 [1871]: 129). En diferentes momentos, el autor, desde un punto de vista marcadamente etnocéntrico y no exento de prejuicios culturales, recoge como rasgos intrínsecos o inherentes de la raza "salvaje" su presunta crueldad (Darwin 1972 [1871]: 115-116) y su disposición por la práctica del infanticidio (Darwin 1972 [1871]: 235). Asimismo, afirma que, igual que ocurre con los monos, la raza negra es más proclive al canto, lo que demostraría su proximidad genealógica (Darwin 1972 [1871]: 474). Incluso, llega a mostrar un clasicismo para con sus congéneres. El biólogo decimonónico llega a afirmar que los pobres y "holgazanes" son seres 
inferiores que se ven arrastrados con suma facilidad por el vicio (Darwin 1972 [1871]: 133). Finalmente, se ha de señalar que, como buen pensador decimonónico, su pensamiento machista también está presente. Considera que las facultades humanas connaturales de la mujer son la intuición, la imitación y la rápida percepción, facultades que, según Darwin (1972 [1871]: 467), son facultades propias de las razas inferiores, aunque no termina de explicar cuál es la razón por la que esas facultades sean inferiores, por qué son propias de las mujeres ni por qué presuntamente son propias de las "razas inferiores". Como han indicado diferentes autores (Armelegos y Goodman 1998: 360-361; Baker 1998: 26-36; Stocking 1982: 95-99), aunque, en la obra de Darwin, el concepto de raza debería ser exclusivamente un concepto biológico (actualmente, de dudosa validez, pues las diferencias genéticas entre las supuestas razas no son significativas), lo cierto es que lo racial y lo cultural se entremezclan y se confunden y, por ello, nunca hubo problemas, por ejemplo, en hablar de "razas inferiores" para aquellos sujetos cuyas sociedades, bajo la óptica etnocentrista, eran "culturalmente poco desarrolladas" (una idea nuevamente censurable para la antropología actual, pues el propio concepto de cultura desarrollada tiende a presentar un sesgo etnocéntrico).

Si una disciplina tan aparentemente objetiva como es la biología estuvo impregnada de prejuicios racistas, lo cierto es que otras disciplinas nacientes pertenecientes a las Ciencias Sociales y las Ciencias Humanas tampoco pudieron evadirse de este sesgo. Así, por ejemplo, la antropología y la psicología fueron disciplinas que no se escaparon de la cosmovisión del momento. En el caso de la antropología, un caso emblemático es el representado por Herbert Spencer. Este autor, a quien menciona Darwin (1972 [1871]: 118-119), fue un antropólogo enmarcado dentro del Evolucionismo antropológico. Defendió como un hecho natural la supervivencia de las clases sociales más "aptas". Por su semejanza con las tesis darwinianas, este tipo de teoría fue tildado como darwinismo social. Sin embargo, como se explica en Harris (2007 [1968]: 105-107), muchas de las ideas que aparecen en Darwin en el campo de la biología, fueron defendidas mucho antes por distintos antropólogos y filósofos en sus correspondientes campos de saber. En este sentido, es indicativo el hecho de que la obra clave de Spencer, titulada Social Statics, trabajo en el que defiende la idea de adaptación o de lucha por la existencia, fue publicada en 1850, es decir, 9 años antes de Orígenes de las especies.

La psicología también fue cómplice intelectual de este clima segregacionista del momento. Muy significativo fue el papel de la denominada frenología en el diseño de esta ideología. La frenología fue iniciada por Franz Joseph Gall (1758-1828), aunque este autor nunca utilizó 
este término, sino que fue popularizado por su discípulo Johann Gaspar Spurzheim (19776-1832). Grosso modo, esta corriente de pensamiento, descartada ya por la psicología actual, defendió que cada potencia o facultad mental (innata) es desarrollada por una parte específica del cerebro y que cuanto más desarrollada está esta facultad, más desarrollada ha de estar la masa cerebral correspondiente, lo que se puede verificar por el perfil del cráneo. Nace con esta la craneometría, método por el cual se cuantificaban las diferencias métricas de los distintos perfiles craneales (Leathy 1998: 210-212, Tortosa y Civera 2006: 54-55, Pereira Poza 2000: 185-192, Gondra 2011: 86-89, o Burgos 2014: 67-68). Algunos discípulos de Gall como George Combe (1788-1858) o Spurzheim (19776-1832) popularizaron la frenología y lo hicieron especialmente al amparo de las teorías segregacionistas del momento. La frenología, conocedora de las teorías darwinistas, defendió la existencia de diferencias craneales dependiendo de la raza: la supuesta superioridad de la raza blanca se traducía en facultades mentales más desarrolladas y, por tanto, en una expresión craneal diferente al de otras razas inferiores como la raza negra. De hecho, no faltaron estudios que relacionaron la semejanza del cráneo de la raza negra con el de las distintas razas de monos (Richards 1997: 1-41 o Twine 2002: 67-88). Igualmente, se trató de relacionar la (in)moralidad de las personas con el desarrollo de unas determinadas facultades mentales innatas y, en consecuencia, con una determinada expresión facial más simiesca. Por ejemplo, se llegó a afirmar que los delincuentes presentaban una "frente baja, rostro ancho, prognatismo, nariz grande o aguileña, dientes prominentes, cejas hirsutas o arrugas precoces" (Cabrera-Guillén 2019: 14).

En esta época, los estudios de Darwin, de la antropología evolutiva y de la frenología mantuvieron entre sí una estrecha relación, de tal manera que había una justificación recíproca de sus propuestas teóricas. No se pueden mirar estos hechos de manera inocente o como una simple anécdota del devenir histórico de las ciencias, sino que, bien al contrario, tuvieron unas consecuencias desastrosas en el siglo XX. El segregacionismo del siglo XIX y del siglo XX fue refrendado por todas estas teorías pretendidamente científicas (Thomas y Sillen 1972; Poliakov 1974; Kevles 1986; Barkan 1992; Kühl 1994; Tucker 1994; Mineau 2004; Sánchez Arteaga 2006; Ehrenreich 2007; Bender 2009; Lombardo 2011; Smith 2015; Olmedo Montes 2015: 510-511; Olmedo Montes y Sánchez-Elvira Paniagua 2005, 24-31). Por ejemplo, la segregación racial en EE.UU. y la dominación impuesta desde la raza blanca hallaron una justificación científica en todas estas disciplinas. Igualmente, la ideología nazista vio sustentada sus tesis en el pensamiento científico racista del momento. La eugenesia, propuesta por Francis Galton, primo de Charles Darwin, fue una práctica abominable 
que se llevó a cabo no solo en la Alemania nazi, sino también en EE.UU. con el beneplácito de la antropología y la psicología racial del momento: en concreto, en EE.UU. se llevó a cabo la eugenesia al esterilizar a mujeres desequilibradas mentalmente ("imbéciles"), alcohólicas o prostitutas y, así mismo, a mujeres de raza negra con el objetivo de garantizar que solo se propagara "la raza superior". Por tanto, no estamos hablando solo de errores y defectos epistemológicos o gnoseológicos, como en siglos anteriores, sino que, ante lo que estamos es de una orquestación científica destinada a cambiar la realidad social del momento, con la que se perpetuaba una injusticia social y se perseguía la progresiva eliminación de todo aquello que no fuera "superior". Es la exterminación de lo diferente, pero ahora con una pretendida base científica.

Finalmente, en este contexto histórico, es relevante el concepto de Volksgeist ("espíritu de un pueblo" o "espíritu nacional") propuesto por Herder (1744-1803) y desarrollado posteriormente por Hegel (1770-1831), especialmente en su Fenomenología del espíritu. Aunque la idea no era totalmente nueva (ya aparece, por ejemplo, en Montesquieu), estos autores desarrollaron este concepto que entroncó perfectamente no solo con el espíritu romántico del momento, sino con buena parte de la ideología germánica. Dicho concepto, que fue tan ampliamente utilizado y manipulado posteriormente, alude, grosso modo, a los rasgos inherentes e intrínsecos que se asocian a un pueblo a lo largo de la historia. La lengua, la religión, las instituciones, las costumbres, etc., constituyen la entidad idiosincrásica de ese pueblo (Ferrater Mora 1979, Palti 1997, Chiaretto 2002 o Arriola 2009). De aquí, es comprensible que, en el futuro, triunfaran lemas tan manidos como "una lengua, una raza y una nación" o similares. Todos los pueblos se asociarían a una raza que presenta unos rasgos culturales que son identificativos y caracterizadores frente al resto de pueblos/razas. Esto es tanto como asumir que existe un predeterminismo por el cual los individuos que pertenecen a un determinado pueblo no puedan ser de otro modo.

\subsection{EL RACISMO EN LA HISTORIA DE LA LINGÜÍSTICA}

La búsqueda de una lengua común y originaria no es un hecho inédito del siglo XIX, pero sí lo es la eclosión de estudios que buscan este objetivo. Y como el propio Saussure (1945 [1916]: 32) indica, la gramática histórica presenta un marcado desarrollo dentro de la filología germana. En el siglo XIX, aparecen figuras clave como los comparativistas Franz Bopp, Jacop Grimm, August Schleicher, o neogramáticos como August Leskien (de origen eslavo) y Hermann Paul. El desarrollo de la gramática histórica se llevó 
a cabo por imitación de las ciencias naturales, influencia del Positivismo científico, influencia del Romanticismo, la consideración de la lengua como soporte de la identidad nacional... (Gallardo Paúls 2000: 71-72).

Según se indica en el trabajo de Blikstein (1992: 104-110), en el que se describe cómo el estudio del indoeuropeo estuvo íntimamente ligado a la corriente supremacista de la raza alemana, Friedrich Schlegel (1772-1829) adoptó una visión naturalista y positivista en la reconstrucción de la lengua originaria por la que el método de las ciencias naturales se trata de aplicar a la filología. Esta metodología fue aplicada por Franz Bopp (1791-1867), padre del método histórico-comparativo, y por August Schleicher (18211861), el "naturalista de la ciencia lingüística". Pero, junto a la metodología naturalista, también se filtraron los prejuicios propios de las ciencias naturales ya descritos anteriormente. Así por ejemplo, habiéndose considerado el sánscrito como la lengua madre u originaria, se realizaron afirmaciones seudocientíficas de acuerdo con las cuales el pueblo indoario era la fuente más pura de los orígenes culturales y lingüísticos (Blikstein 1992: 107). Evidentemente, junto al concepto de pureza cultural y lingüística, iba asociada la existencia de culturas inferiores y degeneradas. Y, dado que, en este momento, la raza estaba ligada a la nación y a la cultura, la inferioridad cultural y lingüística se traducía rápidamente en inferioridad racial.

En esta comparación de pueblos superiores y pueblos inferiores, la filología germánica del siglo XIX ya presenta un sesgo ideológico hacia las lenguas semíticas (y, posiblemente, hacia el pueblo mismo). Por ejemplo, Bopp indica que las lenguas semíticas son de una naturaleza "menos fina" que la lengua sánscrita (Blikstein 1992: 107). Asimismo, en el trabajo de Bernal (1993 [1987]), que estudia los orígenes afroasiáticos (egipcios y fenicios) en la historia de la cultura griega clásica, señala que estas raíces, que fueron asumidas incluso por los propios griegos, fueron ignoradas por la filología germánica solo por una cuestión de racismo intelectual. La filología germánica impuso un origen de la civilización clásica más acorde con la ideología dominante que se fue imponiendo, precisamente, sobre las mismas fechas en las que se publican las obras de Spencer y Darwin. En este sentido, Bernal (1993 [1987]: 400) señala que, desde el siglo XIX (e, incluso, más allá de 1945), hubo un claro intento por ocultar las herencias semíticas en la lengua griega (pese a que la propia Grecia clásica fue consciente de esta herencia).

A finales del siglo XIX, la reconstrucción del indoeuropeo (o indogermánico) siguió ligada a la reconstrucción de ese pueblo puro e intelectualmente excepcional. No existía entonces una división clara entre lo filológico, lo antropológico, lo arqueológico y/o lo biológico, de tal manera que la pureza lingüística debía ir necesariamente ligada a la pureza 
racial y viceversa. Todo el saber del momento estaba destinado a reconstruir el pueblo originario con su respectiva cultura y lengua superiores. Nace entonces la paleontología lingüística, cuya obra capital fue Les Origines Indo-européennes ou les aryas primitifs, publicada entre 1859 y 1863 por A. Pictet, amigo de la familia de Saussure (Saussure 1945 [1916]: 252-253, Harris 2007 [1968]: 122-155, Koerner 1973: 21, Foley y Van Valin 1984: 4 y Villar 1996: 29 y 39).

Tal como se describe en Villar (1996: 33 y 37), dentro de la filología germana aparecen distintos autores cuyas ideas serán asumidas fácilmente por el contexto racista del momento. Así por ejemplo, hacia finales de siglo, el filólogo germano Poesche presentó una visión idealizada del pueblo original y consideró que la denominada raza aria debió (de) ser de cabello rubio y dolicocefálico, es decir, su aspecto físico correspondía con el ideal alemán del momento. Ya en el siglo XX, en 1902, Kossinna descartó el origen asiático, lituano o caucásico de la lengua aria; en su lugar, propuso que este pueblo original, fuente de pureza racial, tuvo su origen en la misma Alemania. Villar (1996: 37) nos indica que la suposición de Kossinna "fue una especie de dogma apenas contradicho por los arqueólogos teutones durante varias décadas, y fue el caldo de cultivo sobre el que se asentaron los ideales racistas del nacional socialismo". Paradójicamente, como señala Villar (1996: 16), el término "ario", término tan utilizado desde el nazismo y ligado a la pretendida pureza racial, es una palabra de origen semítico y no indoeuropeo.

\section{METODOLOGÍA: LA PRENSA HISTÓRICA COMO VENTANA AL CONOCIMIENTO}

Siguiendo los presupuestos metodológicos del proyecto LinPePrensa, nuestra metodología ha sido la de rastrear la prensa histórica del siglo XIX para comprobar la veracidad teórica de lo enunciado anteriormente $\mathrm{y}$, sobre todo, comprobar cómo la cosmovisión científica llegaba al público general mediante la lectura de la prensa.

Nuestras búsquedas se han restringido a la Biblioteca Virtual de Prensa Histórica (https://prensahistorica.mcu.es/es/inicio/inicio.do) y la hemeroteca digital de la Biblioteca Nacional de España (http://hemerotecadigital.bne.es/ index.vm). En esta búsqueda, hemos seleccionado diferentes palabras clave: se han utilizado nombres propios de figuras relevantes (Darwin, Spencer, Gall...), términos de las disciplinas implicadas (filología, lingüística, 
antropología...) y diferentes términos (lengua, indo-germánico, ario, nación, lengua superior, raza superior...). Además, hemos acotado la búsqueda de 1801 a 1900. No obstante, hemos de indicar que la mayoría de los resultados relevantes para nuestro objeto de estudio se ha registrado a partir de la segunda mitad del siglo XIX, especialmente, el último cuarto de siglo. Estos resultados son los esperables, dada la relevancia de la obra de Darwin Origen de las especies, que se publicó en 1859.

Junto a la búsqueda de las anteriores palabras aisladas, se ha examinado el resultado de bigramas (v.gr.: raza aria) y trigramas (lengua y nación). Cuantitativamente, a partir de las expresiones clave seleccionadas, ya se observan algunos hechos interesantes, como es la frecuencia absoluta de algunos de estas expresiones. Especialmente, es relevante la coaparición de algunos términos en los textos periodísticos como son raza aria, raza indo-germánica, lengua superior o el trigrama lengua y nación que se puede encontrar, por ejemplo, en la Biblioteca Virtual de Prensa Histórica. Si los ordenamos cronológicamente y los cuantificamos, estos son algunos de los resultados más interesantes con los que nos hemos encontrado:

\begin{tabular}{|c|c|c|c|c|}
\hline & Raza aria & $\begin{array}{c}\text { Raza indo- } \\
\text { germánica }\end{array}$ & $\begin{array}{c}\text { Lengua y } \\
\text { nación }\end{array}$ & $\begin{array}{c}\text { Lengua } \\
\text { superior }\end{array}$ \\
\hline $1801-1850$ & 0 & 1 & 0 & 0 \\
\hline $1851-1860$ & 0 & 0 & 0 & 0 \\
\hline $1861-1870$ & 2 & 1 & 2 & 0 \\
\hline $1871-1880$ & 13 & 6 & 4 & 0 \\
\hline $1881-1890$ & 16 & 3 & 3 & 2 \\
\hline $1891-1900$ & 23 & 4 & 4 & 2 \\
\hline
\end{tabular}

Tabla 1. Frecuencia absoluta de bigramas y trigramas

Como se puede observar, prácticamente no se encuentra ningún resultado de la combinación de los términos señalados en la primera mitad del siglo XIX. La única excepción encontrada es la de la expresión raza indo-germánica, cuya muestra se encuentra por primera vez en 1850 . Y, prácticamente, la mayoría de los siguientes ejemplos se concentra en el último cuarto del siglo XIX, es decir, tras la publicación de la obra emblemática de Darwin. Es significativo que expresiones que no son propias del ámbito científico como lengua y nación o lengua superior muestren también esta tendencia. Por tanto, se puede decir que aproximadamente a partir de 1875 se localiza la mayoría de los textos periodísticos en los que coaparecen términos con 
una carga connotativa importante. De hecho, buena parte de los ejemplos que nosotros hemos escogido se encuentra en esta franja cronológica.

\section{LA PRENSA DECIMONÓNICA COMO VENTANA A LA IDEOLOGÍA CIENTÍFICA}

\subsection{CieNCIA, IDEOLOGÍA Y PRENSA DECIMONÓNICA}

El contexto científico e ideológico descrito en el apartado 2 llegó a la prensa de España y de las colonias antillanas que conservaba por entonces. Este hecho es significativo porque implica que la ideología racista defendida desde la biología y demás disciplinas no se circunscribió exclusivamente al ámbito científico, sino que dichas ideas trascendieron al público general no especializado, de tal manera que se puede afirmar que existió una interconexión íntima entre la ideología científica y la ideología popular: los prejuicios que actuaron como malla de la descripción científica tuvieron una retroalimentación desde la ciencia misma.

En primer lugar, se ha de señalar que el pensamiento darwiniano tuvo divulgación en la prensa española. Así por ejemplo, en el periódico madrileño Los dominicales del libre pensamiento (revista de corte progresista, según la caracterización de la Biblioteca Nacional de España) aparece la siguiente referencia a los avances llevados a cabo por Darwin en biología:

Después de haber demostrado en nuestro último artículo que la lucha viene á ser conditio sine qua non de la existencia de los seres, nos corresponde hablar de la consecuencia más importante que de este combate universal y gigantesco se desprende; á saber: de la perfectibilidad de las especies ó de lo que en el mundo de la ciencia se conoce con el nombre de selección natural.

Este gran descubrimiento á que llegó el ilustre Darwin después de largos años de incesantes trabajos nos da á conocer cómo nacen y se forman los organismos y como los superiores proceden de los inferiores, en oposición á lo sustentado por la escuela teológica, la cual, en su desconocimiento absoluto de las leyes naturales se empeña en sostener que los organismos vivientes fueron creados por una mano divina y que siempre existieron en el mismo estado en que hoy se encuentran ("La selección natural" de Joaquín Segura, Las dominicales del libre pensamiento, año X, número 504, 20 de mayo de 1892, página 2). 
Pues bien, en los textos periodísticos decimonónicos, se puede encontrar cómo se reproducen fragmentos de la obra de Darwin que son utilizados para criticar el contrasentido de las sociedades avanzadas por perpetuar la existencia de los débiles, es decir, se toman las tesis de Darwin para defender una ideología supremacista. En Revista contemporánea (revista de visión europeísta y, especialmente germana, en la que se recopilaban las aportaciones de diferentes disciplinas científicas), se recoge el siguiente fragmento de la obra darwiniana:

Entre los salvajes, dice [Darwin], los individuos débiles de cuerpo ó de espíritu quedan pronto eliminados, y los que sobreviven se distinguen, generalmente, por su vigorosa y sana complexión. Los civilizados, por el contrario, hacemos todos nuestros esfuerzos para contener la marcha de la eliminación. Construimos hospitales para los tontos, los desvalidos y enfermos; promulgamos leyes para aliviar la indigencia, nuestros médicos agotan los recursos de la ciencia para conservar hasta el último extremo la vida de los enfermos. Motivos nos sobran para presumir que la vacuna ha conservado millares de individuos, que por su constitución endeble, hubieran en otro tiempo sucumbido de viruelas. De este modo en las sociedades civilizadas consiguen los miembros débiles conservar su raza. Ahora bien: cualquiera que haya estudiado un poco la cria y reproducción de los animales domésticos, comprende sin vacilar lo nociva que ha de ser para la raza humana la conservación y propagación de los miembros inferiores. Prácticamente, nos hemos asombrado al observar cómo la falta de cuidados ó solamente los cuidados mal dirigidos, pueden producir rápida degeneracion en una raza doméstica; y nadie, excepto en los casos en que se trata del hombre mismo, es tan torpe é ignorante que consienta la reproducción de sus peores animales (Fragmento tomado de Darwin, Descendencia del hombre. Tomo II, Conclusión, 429, dentro de "La doctrina de la evolución de las modernas escuelas científicas", Joaquín Sánchez de Toca, Revista contemporánea: Año IV-V Tomo XXI Volumen III - 1879 junio 15, páginas 281-282).

Lo mismo cabe decir del trabajo de Herbert Spencer. Este también fue conocido y divulgado en la prensa decimonónica. Por ejemplo, parte de su obra Principios de sociología, apareció en diferentes entregas del periódico Revista europea (revista de corte positivista y evolucionista interesada en autores tales como Haeckel, Spencer, Huxley, entre otros). En el número 208, de 17 de febrero de 1878, aparece la segunda entrega de esta obra (páginas 204-208). Y, del mismo modo, los textos de Spencer que aparecen también son utilizados para insistir en la supervivencia de los más fuertes y para justificar las desigualdades sociales y criticar la filantropía invertida hacia los más pobres, que es calificada como "patraña metafísica": 
"Sostener á los incapaces, á expensas de los capaces, dice Hebert Spencer, es gran crueldad. Es hacer de propósito deliberado acopio de miserias para las generaciones futuras. No puede transmitirse á la posteridad más triste legado que el de la masa de imbéciles, perezosos y criminales, aumentada y multiplicada en número siempre creciente. Ayudar á la multiplicacion de los malos es preparar perversamente á nuestra descendencia un ejército de enemigos. Con razon nos hemos de preguntar si la estúpida filantropía, que no piensa sino en aliviar los males del momento, empeñándose en no tener para nada en cuenta los males indirectos, no produce á la postre mayor suma de miserias que el más extremado egoismo... Hay algo, sin embargo, que merece reprobación áun más severa, y es el malbaratamiento de capital, inspirado en una falsa interpretación de la máxima "que la caridad borra muchos pecados". Debemos reconocer que hay un elemento de verdadera bajeza en las personas imbuidas en tan falsa interpretación de la caridad: trabajan por adquirir un buen puesto en el otro mundo, sin preocuparse del daño que obrando asi causan á sus semejantes... Son egoistas de primera fuerza, á quienes con tal de salvarse, les importa poco el mundo y la humanidad que menosprecian... Los que se proponen proteger á la masa de los incapaces, producen un mal incontestable, entorpecen ese trabajo de eliminación de la naturaleza por el cual la sociedad ella misma se depura sin cesar. Sólo contribuyen á conservar los malos y destruir los buenos sin procurar ninguna de las ventajas que pueden producir el otroismo (la filantropía) individual (Fragmento de Herbert Spencer, Introducción a la ciencia social. "Preparación por la biología", pág. 369. Dentro de "La doctrina de la evolución de las modernas escuelas científicas", Joaquín Sánchez de Toca, Revista contemporánea: Año IV-V Tomo XXI Volumen III - 1879 junio 15, páginas 280-281).

Desde luego, [el darwinismo] rechaza con igual desprecio la antigua doctrina del derecho natural y la moderna teoría democrática de los derechos del hombre. Declara que no concibe lo que pueden ser esos derechos inherentes á la persona humana, y todas esas patrañas metafísicas que hoy se formulan con el nombre de derechos imprescriptibles, inalienables, anteriores y superiores á toda ley escrita. El dogma de la igualdad democrática le parece también al darwinismo un sueño de utopista que no puede tener otro fruto que el de engendrar horrible anarquía. Las desigualdades sociales son consecuencia necesaria de la seleccion sexual: el mejor individuo escoge la mejor hembra, esta pareja transmite sus cualidades á su descendencia, y así se forma la raza superior. A las clases superiores elaboradas por la selección sexual, pertenece de derecho la soberanía social y la dirección de las masas. Las doctrinas sociales y políticas que quiere fundar la escuela de la evolución, son, pues, como lo declara uno de sus más brillantes mantenedores 
"radicales en grado superior á todo lo que concibe el radicalismo actual, y conservadoras tambien en grado superior á todo lo que concibe la moderna escuela conservadora" (Herbert Spencer, Introduccion á la ciencia social, cap. XVI, Conclusion). Aspira, por tanto, á ser revelodora de dogmas morales y principios del todo nuevos ("La doctrina de la evolución de las modernas escuelas científicas", Joaquín Sánchez de Toca, Revista contemporánea: Año IV-V Tomo XXI Volumen III - 1879 junio 15, páginas 279-280).

En los distintos escritos de la prensa decimonónica, es una constante la defensa de la evolución como un camino hacia la perfección de las especies, es decir, se defiende una visión teleológica de la evolución que no casa en absoluto con la concepción biologicista actual de la evolución. En este camino de la evolución, el mejor destino descrito para las especies débiles o inferiores es su desaparición:

[...] quizás después de miles ó millones de siglos una nueva especie animal superior venga á reemplazar á la actual especie humana, porque si en la série de la evolucion de los organismos vemos que es una verdad el trasformismo defendido por Lamark y Darwin, y las razas humanas no son otra cosa que transformaciones de organismos anteriores, verificadas á impulsos de los medios circundantes, marchando siempre en sentido progresivo, y siendo las especies posteriores mas perfectas que las anteriores de donde proceden, motivos hay para esperar que así como los antropóideos han dado origen al hombre, de igual suerte podrá salir de la especie humana otra especie superior á la nuestra ("Sociedad espiritista española", La Revelación, año X, número 4, 20 de abril de 1881, página 258).

Lo malo es, si hemos de creer á otros sabios, que ya es tarde para imitar á los pigmeos. Nuestras grullas han roto el cascaron: la raza que ha de acabar con nosotros, como nosotros acabamos con los antropiscos, vive y se extiende por el mundo y le domina, y ha empezado la obra de aniquilamiento. Darwin, Schaafhausen y otros doctos ingleses y alemanes, han explicado bien la teoría de que lo que es mejor y más fuerte debe suplantar á lo que es peor y más débil. Las razas decaídas y endebles, que se quedan en grande atraso, que no pueden seguir, ni á remolque y á larga distancia, á otras razas más enérgicas é inteligentes, están condenadas á perecer y de hecho perecen. Al contacto de toda civilización muy superior, los hombres de una civilización muy inferior se mueren todos. Los Portugueses y Españoles, como no estábamos muy civilizados, no dimos muerte á todos los negros é indios con quienes entramos en relación cuando nuestros descubrimientos y conquistas; pero, según parece, los Ingleses y los Yankees, como más adelantados en civilización, tienen la mision de acabar con todos. 
[...] Toda raza inferior, con respecto á otra superior, es un eslabón ó un anillo de la cadena que une al hombre con la naturaleza bruta, y según lo explica satisfactoriamente el ya citado Doctor Schaafhausen, es una ley ineludible del progreso, que este eslabón ó anillo se rompa y aniquile ("Leyendas del antiguo oriente" de Juan Valera. Revista de España, año III, tomo XV. 1870, página 182-183).

En el primer fragmento, recogido en una revista destinada al estudio de los espíritus (una investigación que se entendía por entonces como algo científico), se recoge la idea de que la evolución es un proceso perfeccionista (cada especie surgida nueva es mejor que la anterior). La conclusión que se parece inferir de este camino es que las especies inferiores deben desaparecer, pues así lo establece la ley natural de la evolución, entendida como ley del progreso. Esta es la idea que aparece en la Revista de España, revista que fundó José Luis Albareda, que trató de ser ecléctica y en la que escribieron autores relevantes como Benito Pérez Galdós, Emilia Pardo Bazán, Giner de los Ríos, Ramón de Campoamor, Cánovas del Castillo, entre otros (Ballantyne 1990: 332-342). En el ejemplo citado, es Juan Valera, autor de Pepita Jiménez, quien mantiene esta última tesis. Si se tiene en cuenta que el pensamiento de Juan Valera acabó siendo afín a las tesis relativamente progresistas de Sagasta y que fue un defensor del abolicionismo de la esclavitud (Juan Lovera 1975), sin duda, resulta paradójica la defensa de la exterminación de las civilizaciones inferiores por parte de aquellas que se suponen que son superiores.

$\mathrm{Y}$, como se ha indicado, la psicología y, especialmente, los estudios de la frenología se unieron a este clima ideológico. Según esta postura, las razas superiores eran aquellas que presentan de forma innata facultades más desarrolladas que, además, se mostraban físicamente en el tipo de cráneo. Así se pueden observar en los siguientes fragmentos de La Academia: revista de cultura hispano portuguesa, latino-americana (revista cuya finalidad era plasmar las novedades más importantes de la cultura y de la ciencia nacionales y trasatlánticas y cuyo lema inicial reza por la ciencia y por la patria) y de la Revista de España.

Uno de los más importantes resultados de los experimentos de Mr. Le Bon parece ser que: el desarrollo de la inteligencia tiene una relación íntima con la forma, la estructura y el volumen del cerebro. El volumen es uno de los principales factores. Los cerebros más voluminosos pertenecen, en la especie humana, á las razas mejor dotadas bajo el concepto intelectual, y, en cada raza, á los individuos más inteligentes. Constituye la superioridad de una raza con respecto á otra, el que la raza superior, cuenta muchos más cráneos voluminosos, que la raza inferior. 
El peso del cerebro, ó del volumen del cráneo presenta diferencias considerables entre los individuos de una misma raza. Estas diferencias se manifiestan de una raza á otra, y son tanto mayores cuanto más elevada está la raza en la escala de la civilización. Así, pues, se ha notado que la diferencia entre el volumen de los cráneos masculinos adultos mayores y menores es de: 148 centímetros cúbicos en el gorilla; 204 en el negro; 353 en los antiguos egipcios; 472 en los parisienses del siglo XVII y 593 en los parisienses contemporáneos. La talla tiene una influencia sobre el volumen del cerebro, aunque mínima. Dada una estatura igual, la mujer tiene un cerebro mucho ménos pesado que el del hombre. La diferencia existente entre el peso del cerebro, y por consiguiente el volúmen del cráneo vá creciendo constantemente á medida que se asciende en la escala de la civilización, de manera que, bajo el punto de vista de la masa del cerebro y subsiguientemente de la inteligencia, la mujer tiende á diferenciarse más y más del hombre. La diferencia, por ejemplo, existente entre el promedio de los cráneos de los parisienses contemporáneos y los de las parisienses, es casi doble de la que existía entre los cráneos masculinos y femeninos de los habitantes del antiguo Egipto. La circunferencia del cráneo, de la que depende el volúmen del cerebro, tiene íntima relación con el estado de la inteligencia. Estudiando comparativamente las curvas de la circunferencia del cráneo, con la de la cabeza, el volúmen y el peso del cerebro, hánse podido apreciar las relaciones que existen entre estos diversos valores. Así, por ejemplo, una cabeza cuya circunferencia es de 57 centímetros y su volúmen es de 1550 centimetros cúbicos, y el peso probable del cerebro contenido en este cráneo será de 1250 gramos ("La quincena parisiense", La Academia: revista de cultura hispano portuguesa, latino-Americana: Tomo IV Número 4 - 30 julio 1878, página 55).

El símil de la girafa explica esto que no hay más que pedir. La girafa era en un principio una como cabra montes ó gacela; pero se fué á vivir á parajes donde no habia yerba, y tuvo que alimentarse de las altas ramas hojosas de los árboles. Andaba, por lo tanto, casi continuamente estirando el pescuezo y las patas delanteras, y tal fué lo afanoso de este ejercicio, durante muchas generaciones, que las patas delanteras y el pescuezo se le alargaron, y casi sin sentir vino á convertirse en girafa. Asi, mutatis mittandis, se explica el orígen de las demás nuevas especies, cada vez mejores. Aplicada al hombre la susodicha teoría, debe entenderse que el inglés, á fuerza de discurrir y cavilar, ha ido empujando para arriba toda la parte anterior de su cráneo y haciendo más capaces los senos, y más gruesas las protuberancias de la causalidad, comparación y demás facultades mentales superiores. Al mismo tiempo los laberintos ó circunvoluciones del meollo ó encéfalo se han hecho más tortuosos y complicados, de lo cual depende, sin duda, el pensamiento, así como 
de la masa y volumen de los sesos que se han hecho mayores. Y por último, la buena alimentación ha acostumbrado el estómago inglés á extraer y á asimilar á su organismo mayor cantidad de fósforo, que es el ingrediente principal con que el pensamiento se confecciona, según Moleschott, Büchner y un boticario amigo nuestro. Lo que es Edgardo Quinet, en su ya citada Creación, saca de aquí un luminoso corolario. Casi prueba que con el Cesarismo se achican los sesos, se hacen más livianos y tienen menos circunvoluciones. Los sesos de cualquier francés pesan hoy menos y tienen menos laberintos que cuando comenzó á reinar Napoleón III ("Leyendas del antiguo oriente", de Juan Valera. Revista de España, año III, tomo XV. 1870, páginas 183-184).

Estas supuestas diferencias biológicas apuntadas iban asociadas a diferencias sociales y políticas. En el ámbito social, resurgen las ideas platónicas: las teorías científicas del momento justificaban las diferencias sociales, de tal manera que la existencia de una aristocracia social era vista como un hecho derivado de las propias tesis de la evolución:

El estudio de la naturaleza y de la sociedad humana nos dan una relación de desigualdad siempre creciente, considerados los organismos y los séres que viven en ella en un tiempo dado; mas si la consideracion se hace extensiva al terreno de la dinámica social, vemos cómo la transformación contínua de los séres hace cambiar los factores de las jerarquías, pero jamás las jerarquías mismas.

Desde luego que la division del trabajo en la naturaleza y en la sociedad solo es posible en la desigualdad de órganos y la consiguiente diversidad de organismos; hemos de convenir en que la categoría es la ley de naturaleza orgánica y social [...].

Por lo que respecta á las condiciones fisiológicas que determinan una categoría particular en cada época, estará en primer lugar colocado el hombre cuyas manifestaciones de un órden intelectual sean más diversas é intrínsecamente más importantes y complicadas. El hombre que puramente digiere y secreta, ejercitando el cerebro lo ménos posible, ocupa el lugar inferior en la categoría social. Las autocracias humanas tienen el privilegio de las más altas funciones sociales.

[...] Las aristocracias se han ido sucediendo y han ido gobernando eternamente. Lo mejor, lo más escogido, los séres más fuertes han dominado y han vencido siempre en la lucha por la existencia. La supremacía obtenida por los séres más fuertes, es debida á su organización superior y consiguiente facultad de adaptarse al medio ambiente. Darwin ha desarrollado estas leyes en su Origen de las especies; Bagehot y otros las han aplicado á la ciencia social ("Contribución al estudio de la ciencia social”, de P. Estasen. Revista contemporánea, Año III-IV, Tomo XIII, Volumen IV - 28 de febrero 1878, páginas 432-433). 
En el ámbito político, se invita al Estado a tomar las medidas necesarias para no ir contra naturam y a no permitir que se propaguen los débiles en la sociedad. En su lugar, el Estado, según estas tesis supremacistas, debería autoprotegerse y no invertir ningún tipo de recurso económico en el auxilio de los débiles con el fin de que se perpetúen "los más aptos":

¿Cuál es el principio fundamental que en el órden social y político debe, segun la escuela [darwinista], constituir la preocupación constante de los legisladores? Es el mejoramiento de la humanidad fundado en un conocimiento exacto y profundo de las leyes biológicas, como la de la selección sexual, que presiden al mejoramiento de la especie. El legislador debe imitar á la naturaleza y ayudarla en su trabajo de eliminacion de los séres imperfectos. Para nada se han de tener en cuenta los intereses y derechos del individuo, sino los intereses y derechos de la especie. Lleva la escuela su absoluto menosprecio del derecho individual hasta el extremo de hacer alarde de la más profunda aversión á todas las obras de filantropía y caridad que tienen por objeto amparar al necesitado de la clase inferior ("La doctrina de la evolución de las modernas escuelas científicas", Joaquín Sánchez de Toca, Revista contemporánea: Año IV-V Tomo XXI Volumen III - 1879 junio 15, página 280).

Incluso, entre las opciones aportadas en defensa de una sociedad "más fuerte", se observa alguna defensa de propuestas eugenésicas destinadas a eliminar a los "más débiles" de la sociedad. Sin lugar a dudas, se puede

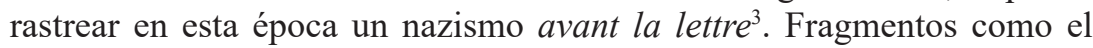
presente parecen defender una postura eugenésica que será propia no solo de la Alemania nazi (aunque, sin duda, fue un ejemplo extremo y paradigmático), sino también de otros países occidentales supuestamente avanzados como lo fue Gran Bretaña, Francia o EE.UU. (Thomas y Sillen 1972; Poliakov 1974; Kevles 1986; Barkan 1992; Kühl 1994; Tucker 1994; Mineau 2004; Sánchez Arteaga 2006; Ehrenreich 2007; Bender 2009; Lombardo 2011; Smith 2015; Olmedo Montes 2015: 510-511; Olmedo Montes y Sánchez-Elvira Paniagua 2005, 24-31).

\footnotetext{
3 En este sentido, es sintomático un fragmento como el siguiente en el que se apunta a un posible sentimiento de superioridad racial de Alemania: "Sabido es que despues de la última guerra Alemania exageró considerablemente las consecuencias de sus triunfos militares: la supremacía de sus armas y de su política la cándida pretension de ser una raza superior por la inteligencia, la ciencia y la moral, no le satisfacían" ("El socialismo en Alemania" de Leveigy, Revista europea: Año V, Tomo 12, número 247, 17 de noviembre 1878, página 1).
} 
¡Hermosa moral! En mal hora vino el cristinanismo á lanzar anatemas contra el infanticidio, y condenar la esclavitud, y declarar á los hombres hermanos en Cristo, y ensalzar la caridad por cima de todas las virtudes. El mundo antiguo conocía mejor que los siglos cristianos las leyes biológicas de la moral. Aquella sociedad edificada sobre la institución de la esclavitud, daba muestras de tener penetracion mayor que los modernos de la inferioridad originaria de algunas castas humanas. Aquella sociedad que no conocía ni hospitales, ni asilos, ni ninguna otra de las instituciones de caridad que ha levantado el espíritu cristiano para socorro del desvalido y necesitado y amparo de la humanidad miserable y doliente; aquella sociedad que abandonaba, vendía, ahogaba ó despeñaba por el Taigeto al niño contrahecho, practicaba mejor que las sociedades actuales las leyes del progreso humano, pues cumplía por misterioso presentimiento la ley suprema de la eliminación de las inferiores de cada especie que Darwin había de revelar á la humanidad ("La doctrina de la evolución de las modernas escuelas científicas", Joaquín Sánchez de Toca, Revista contemporánea: Año IV-V Tomo XXI Volumen III - 1879 junio 15 , página 283).

Una cuestión polémica que se debatía en la segunda mitad del siglo XIX era la moralidad y la conveniencia de mantener un sistema de esclavitud en las antiguas colonias españolas, como era Cuba o Puerto Rico. De esta manera, las ideas seudocientíficas tuvieron repercusiones políticas notables. En el contexto ideológico descrito, las teorías darwinistas y frenológicas eran asumidas en este debate en favor de la esclavitud, tal como se muestran en periódicos de las Antillas, como es el primer caso:

Pero la audacia de la opresión va aún más allá. En su afán constante de investigar de qué suerte se ha realizado su aparición sobre la tierra, el hombre ha llegado, en fin, á encontrar un método verdaderamente científico, "puesto que no exige la intervención de ningun poder sobrenatural, y que tiende á explicar los hechos por la accion de leyes regulares" (V. Girard de Raille. Les peuples de l'Afrique et de l'Amérique). Mediante este instrumento, el análisis del orígen de la especie humana ha tomado caractéres de seriedad indiscutible. No obstante, hasta en ese terreno resbaladizo el esclavismo toma posición para el combate, deduciendo de la racional teoría de la evolución y del trasformismo -entrevista por Lamark, Geoffroy Saint Hilaire, Goethe, Lyell, Schleicher, comprendida perfectamente por Wallace, y promulgada por tanta grandeza como concisión por Darwin- que la esclavitud, "sometimiento á una raza superior -como la definia uno de su más resueltos mantenedores- era el estado natural y permanente del negro" (Bigelow, Les Etats Units en 1860, Discurso pronunciado en Savanah por Mr. Stephens) ("Los argumentos esclavistas", de Juan Gualberto 
Gómez, Revista de las Antillas: periódico de intereses económicopolítico-sociales de las islas de Cuba y Puerto Rico: Tomo III Número 6 Año III Número 84 - 1884, Febrero 27).

A los que creen que la esclavitud, tal como se halla establecida en Cuba, reduce al negro a una situacion depresiva de la dignidad y de la inteligencia del hombre blanco, opone el Sr. Olivares esta curiosa observación:

"El esqueleto de un negro, dice el Dr. Van Ewrie de Nueva-York, está de tal modo formado, que si se colocase sobre él la cabeza de un europeo, no podría conservar su equilibrio. Resulta, pues, añade, que los filántropos que pretenden elevarle al nivel de su propia inteligencia, solo conseguirian hacerle incapaz de guardar la posición vertical".

Se ha declamado y se declama mucho, suponiendo que la condicion del negro esclavo en Cuba es muy dura; pero de poco sirven las declamaciones cuando los hechos las contradicen completamente ("La esclavitud en Cuba". La libertad. Periódico moderado, número 371, 25 de enero de 1865 , página 1 ).

No faltaban escritos periodísticos que atacaban esta línea argumentativa racista que aunaba ciencia y defensa del esclavismo y que, por el contrario, defendían que, bajo un contexto educativo y cultural adecuado, el hombre de color podía desarrollar (casi) las mismas facultades que el hombre de raza blanca. Sin embargo, los fundamentos ofrecidos no son propuestos desde tesis científicas, sino que el fundamento último es religioso:

Los fisiologistas han hecho públicos los resultados de sus pacientes investigaciones. La anatomía lo ha escrutado y comparado todo. Los misioneros, los viajeros, los sabios han aportado unos tras otros los materiales del edificio científico, y sin embargo, cada vez que se encuentran esas figuras negras, siéntese uno tentado de preguntar todavía: ¿Por qué?... ¿Por qué?

Dios es el principio de la bondad y de la onmipotencia. He aquí mi punto de partida. El negro existe; luego ha sido creado con un fin particular. Este fin es el que se necesita buscar, por supuesto que por intuicion sabemos que debe existir.

Soy un ardiente adversario de la preocupación que hay contra esta malaventurada raza. [...] damos pasos gigantescos, y en nuestro necio orgullo, proclamamos á nuestra raza superior. Y en realidad no hay nada de esto, absolutamente nada.

Negros trasportados en su más tierna infancia á Europa, educados con una justa ponderacion de firmeza y ternura, recibiendo una instrucción sólida, proveerían á la sociedad de hombres útiles é inteligentes, cuyo espíritu franquearía todas las edades para brotar en el seno de nuestra 
civilizacion y manifestarse en ella por las más varias aptitudes ("El negro" de Ch. Pradez. El Gobierno. Diario político de la tarde. Año III, número 856,31 de octubre de 1874, página 1).

En este sentido, hay que indicar que el debate fe y ciencia se hacía ya patente con la aparición del darwinismo, tal como se puede observar en los dos siguientes fragmentos, con dos visiones antagónicas respecto al darwinismo:

El galicalismo y el protestantismo engendran así la regalía, que es otro aspecto de la repugnancia al reino exterior de Jesucristo. Y de grado en grado llegareis en la disquisición histórica, como el mundo infortunado ha llegado en el dominio de los hechos, á la erupcion del liberalismo, postrera consecuencia y fórmula culminante del sofisma que niega á la Iglesia lo que es de Cristo, traslada luego al soberano lo que es de la Iglesia, y acaba, en los asombrosos escándalos de este siglo, por blasfemar de la Iglesia, apostatar de la fé, y negar á Dios, subordinando a los hombres á la voluntad caprichosa de los partidos ó de los tiranos, preconizada como una ley fatal de la fuerza y de la materia, generatrices de la vida y de las sociedades, y de todo lo que se vé, porque el naturalista del siglo décimo nono niega lo que no pesa en sus balanzas ni destila en sus alambiques. (¡Muy bien! Aplausos.)

Darwin, Spercer y Hubner... son sus profetas. Para nombrar sus caudillos tendría que bajar hasta Garibaldi, y sus cómplices de Porta Pía... (Bravos y aplausos atronadores) ("Esquela de Don José Manuel de Estrada", El Siglo futuro. Diario católico, año XII, núm. 3524, 11 de diciembre de 1886).

A las exageradas concepciones de la teología se oponen con formidable séquito de adeptos, con la deslumbrante antorcha de la verdad y la razón, los principios universales de la filosofía positiva; á San Pablo y á Santa Teresa de Jesús se oponen el maestro Darwin y el maestro Renán y el maestro Comte; á la literatura añeja, exótica, impracticable, especie de señuelo que atrae á los ilusos, se enfrenta la literatura nueva, la literatura que bebe en las claras fuentes de la razón, de la democracia ("Reflexiones" de R. Marcano Rodríguez, Las dominicales del libre pensamiento, año XII, número 631, 14 de septiembre de 1894, página 2).

\subsection{PRENSA HISTÓRICA DECIMONÓNICA, IDEOLOGÍA Y FILOLOGÍA}

Como hemos indicado en el punto 2.2, la filología hispánica de la segunda mitad del siglo XIX no fue, en absoluto, ajena a la ideología supremacista que impregnó buena parte del resto de las ciencias decimonónicas. La filología también participó de este caldo de cultivo descrito anteriormente. 
En primer lugar, se ha de indicar que la filología asume como paradigma de investigación aquel que es propuesto desde las ciencias naturales y, en concreto, desde la biología, tal como se apunta en el trabajo de Blikstein (1992) anteriormente citado. Con las oportunas diferencias existentes entre un ser vivo y una lengua, la prensa recoge esta asunción del método naturalista. De esta manera, la filología se revelaba una ciencia más dentro de las ciencias decimonónicas del momento:

Diez nos presentó las seis lenguas romances cual hijas y herederas espirituales de la eterna Roma y explicó su desarrollo cual proceso legal. "El espíritu de todas las ciencias modernas, dice el Sr. Foerster, es el método histórico-genético que creó á la vez la filología comparativa, la geología y el darwinismo, la teoría de descendencia, aunque hay una diferencia muy grande entre la naturaleza que se desarrolla sin saberlo y las lenguas, manifestándose estas últimas el espíritu, la centella de Prometeo". Ha de ponerse, pues, Diez junto á los Darwin y Helmholtz; pero los fines del gran gramático no eran los fines prácticos de las ciencias naturales, sino que en actividad era meramente ideal, descubriéndonos las venas más secretas del alma popular ("El centenario de Federico Diez padre de la Filología romance", de Juan Fastenrath. La Ilustración artística, año XIII, número 647, 21 de mayo de 1894, página 323).

Según se indica en Robins (2000: 251), Schleicher fue el primero en establecer una conexión temprana entre las tesis darwinistas y la filología. En su tratado Teoría darwiniana y lingüística, indica que la reconstrucción de la historia de las lenguas es análoga a la reconstrucción de la filogenia evolutiva. Se inicia con este autor un cambio de visión por el que "la teoría darwiniana de la evolución por la supervivencia reemplazó a la evolución perfeccionista de Humboldt". En el fragmento seleccionado, se puede observar plasmada, unos 30 años más tarde, esta idea en la prensa hispánica. Este hecho es relevante porque es lo que da legitimidad para reproducir los excesos racistas en la propia filología.

En este sentido, se ha de señalar que el hecho de que la filología asumiera el método de la biología como suyo propio no puede ser calificado per se como un hecho censurable. Sin embargo, el problema reside en que, junto a este método científico, también se asumieron las tesis supremacistas recogidas en los anteriores apartados. En concreto, la raza indo-germánica, recreada desde la filología germánica, es descrita como esa raza superior frente al resto de razas inferiores, entre las que se situaría una hipotética raza lémur, que se defendió en este siglo, aunque sin ningún fundamento científico (Ramaswamy 2004): 
Así, pues, las condiciones de la evolucion histórica serán la de expontaneidad y libertad realizadas en una raza superior, último grado de la evolucion humana en un momento histórico (en la actualidad la indo-germánica), la cual en virtud de la ley de la seleccion y de la herencia predominará cada dia más, si no surge otra interior que la contrarie ó de su seno que la absorba ("La teoría de la evolucion" de P. Estasén. Revista contemporánea: Año V Tomo II. 30 de agosto 30, página 233). En la especie humana ocupan el primer término de la categoría de los individuos de la raza indogermánica; el último término está destinado sin duda á los primitivos habitantes de la Lemuria ("Contribución al estudio de la ciencia social”, de P. Estasen. Revista contemporánea, Año III-IV, Tomo XIII, Volumen IV - 28 de febrero 1878, página 432).

Del mismo modo que, bajo este paradigma ideológico, se defendía que las razas superiores estaban más desarrolladas intelectualmente y tenían rasgos físicos que los caracterizaban (v.gr.: la forma del cráneo), las razas superiores solo podían presentar una lengua que estuviera mucho más desarrollada acorde con su desarrollo intelectual. De esta manera, se proponía una armonía entre el físico, el pensamiento y la lengua. Por el contrario, las razas inferiores solo podían desarrollar un lenguaje gestual, próximo al de los animales. Su pensamiento inferior no les permitiría desarrollar un lenguaje más complejo con el que pudieran utilizar conceptos abstractos. En el presente pasaje periodístico, titulado de forma significativa "El lenguaje y la teoría de la evolución", se muestra este ideal:

El salvaje, como los espíritus poco desarrollados, carece de ideas generales, y son muchas las tribus que poseyendo palabras para designar cada uno de los objetos conocidos, carecen de signos propios para expresar las ideas abstractas. Los Tasmanios para indicar que una cosa es dura dicen que es, "como una piedra" y para indicar que una cosa es redonda dicen que es "como la luna." Estas tribus con un lenguaje sencillo compuesto solo de gestos y gritos instintivos pueden expresar á maravilla todas sus ideas. El ejercicio limitado de sus facultades intelectuales no exige medios más complejos.

Nadie duda de que los animales poseen un lenguaje en relacion con el desarrollo de su inteligencia y suficiente para que entre sí puedan comunicarse sus impresiones. Hasta las hormigas poseen en alto grado esta facultad, y podríamos citar á este propósito un sinnúmero de observaciones de pacientísimos naturalistas [...]. El hombre primitivo posee un lenguaje natural espontáneo, en armonía con su inteligencia y muy parecido al de los animales superiores. El gesto, la interjección expresada por gritos y los sonidos imitativos son sus elementos 
componentes ("El lenguaje y la teoría de la evolución”, de J. Gres. $L a$ Ilustración (Barcelona). Año II, número 61, 1 de enero de 1882, página 3).

En esta cita, se reproducen clichés y estereotipos sobre las lenguas no occidentales que se repitieron más allá del siglo XIX (Harris 2007: 69-121; Linton 2000: 37-84; Velasco Maíllo 2007: 23-56; Vinatea Serrano 2008: 2949): supuestamente, su sintaxis es pobre, su vocabulario es limitado y sus hablantes son incapaces de expresar un pensamiento abstracto y, si lo hacen, tienen que recurrir a circunloquios en lugar de emplear un único término. Además, el desarrollo lingüístico es simétrico a su desarrollo intelectual. En este sentido, se puede observar que se establece una relación causal y necesaria entre cultura inferior ( $y$, posiblemente, raza inferior) y lenguaje y pensamiento subdesarrollados. Sin duda, en el fragmento elegido, se puede observar cómo los prejuicios supremacistas de la biología hallaron eco en la filología misma. A principios del siglo XX, algunos autores como Boas, muy críticos con este tipo de evolucionismo antropológico, trataron de poner freno al tipo de interrelaciones establecidas que carecían de justificación científica y, sobre todo, iniciaron el camino para revalorizar cada lengua en su singularidad (Vinatea Serrano 2009: 68-69; Harris 2007: 221-222). Las diferentes lenguas disponen de mecanismos muy heterogéneos para expresar el pensamiento y todos son igualmente válidos: unas lenguas pueden presentar un vocabulario muy complejo para determinados campos semánticos en detrimento de otros campos, mientras que otras presentan una sintaxis muy diferente respecto a las lenguas occidentales y, no por ello, son lenguas gramaticalmente menos complejas.

Asimismo, se ha de indicar que la denominación de raza indoeuropea fue sinónima a raza aria, un hecho que es relevante por la carga connotativa que tendrá en el futuro dicho término. Así por ejemplo, podemos encontrar la siguiente identificación en los siguientes fragmentos seleccionados:

Nos dice que Nemrod, nieto de Cam, el Belo de los historiadores profanos, fundó sobre el Eufrátes á Babilonia, de donde procedieron los caldeos (raza camita); que Assur, hijo de Sem, fundó cerca de allí, sobre el Tírgris, á Nínive, de donde procedieron los asirios (raza semita); y la semejanza de nombres induce á creer que Madia, hijo de Jafet, fue padre de los medos (raza aria ó indogermánica) ("Más allá de la tuma" de Abdon de Paz. Revista contemporánea, 30 de octubre de 1876, página 166). 


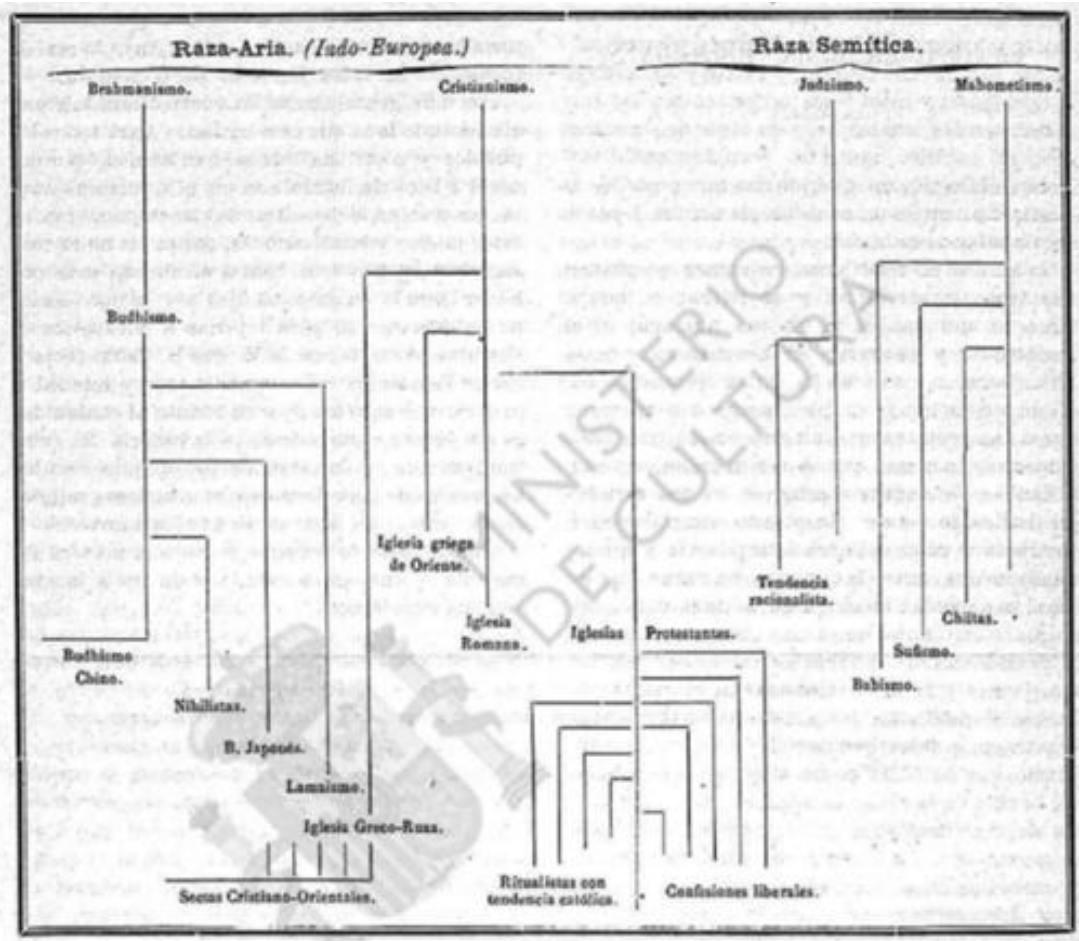

"La historia de las religiones" de Francisco P. de Canalejas. Revista Europea, número 11, año I, 10 de mayo de 1874, página 322.

El hecho de que se hable indistintamente de lo indoeuropeo (o indogermánico), que remite al origen cultural de Occidente (por lo que curiosamente parece ignorarse la lengua sánscrita, la lengua más antigua de la que se tenía testimonio en aquel momento) y de lo ario, que se asocia con lo auténtico y lo inmaculado, no es un hecho baladí, sino que pone de relieve, por contraste, el carácter impuro del resto de lenguas/culturas que no proceden de ese tronco común. En este caso, esa lengua (o cultura) es la semítica. De este modo, la reconstrucción filológica contaba con una terminología que no es, en absoluto, inocente, como tampoco lo es el trasfondo ideológico del que se nutrió.

En este sentido, cabe recordar que, como ya se adelantaba en el apartado 2 , la raza semítica es vista siempre como una raza inferior frente a la raza aria o indoeuropea. La raza semítica, incluso cuando aparentemente se la defiende, aparece como una raza irracional que debe imitar la raza más civilizada y con mayor progreso: 
El genio oriental, el genio semítico es religioso, es sobrenaturalista por excelencia. El indo-europeo es libre y reflexivo, fuerte é inclinado al progreso.

[...] El espíritu ario triunfa de todo. El espíritu semítico desdeña la ciencia, tiende a la supresión de la sociedad civil; "en su espantosa simplicidad quiere detener el cerebro humano en sus funciones más elevadas, cerrarlo á toda idea progresiva, á todo sentimiento delicado y verdaderamente humano, á toda investigación racional, como dice Renan, para ponerlo frente á frente de esta eterna tautología Dios es Dios".

El porvenir eliminará, pues, el espíritu semítico del haz de la tierra. Hoy por hoy, Europa impone ya el suyo á los asiáticos. Lo que hoy comienza, no tardará mucho en verse realizado. Todos los semitas por adaptación llegarán á ser indoeuropeos, y aceptarán el derecho, la libertad y el respeto á lo humano.

¿Habrá sido inútil á la humanidad el elemento semítico? No. Ha contribuido al progreso por oposición, por contraste. A no haber discutido en vano la escolástica en pos de lo absoluto, no buscarían hoy los filósofos las leyes del pensar en las ciencias positivas, desengañados del fracaso de aquel método ("Del elemento semítico en la historia" de Pompeyo Gener, Revista contemporánea, 27 de abril de 1877, páginas 483-484).

Finalmente, se ha de indicar que el pensamiento herderiano/hegeliano está presente en la prensa histórica. En concreto, se asume que la lengua y la literatura están inherentemente ligadas a la raza y a la nación. Por tanto, se asume la unidad de una nación, una raza, una lengua y una cultura.

[...] la lengua y la literatura patrias prefiérense siempre á las extrañas. Producto son, tanto el idioma como las letras, del carácter nacional, de las cualidades de la raza, cuyos defectos y virtudes pregonan. Así, hállase en el idioma nativo la forma más adecuada del pensamiento, y en la literatura propia el reflejo más exacto de los gustos, las aspiraciones y las peculiares tendencias del espíritu ("Los mejores libros”, Brantome, La época, año XLV, número 14764, 22 de octubre de 1893, página 2).

Herder, que fue un defensor del monogenismo (tesis según la cual el origen del hombre procede de una única raza) y que aceptó la existencia de lenguas inferiores/superiores cuya perfección se fundamentaba en la evolución de las lenguas (en concreto, hipotetizó un primer estadio formado por una lengua con un vocabulario muy simple que daría paso, con el tiempo, a lenguas con mayor léxico y con una sintaxis emergente), consideró que el lenguaje y el pensamiento se desarrollaron en el hombre de forma simultánea e interdependiente, de tal manera que aquella raza que tuviera un pensamiento simple solo podía tener un lenguaje simple y viceversa (Robins 
2000: 194-196). Por este motivo, las tesis herderianas casaron muy bien con las disciplinas supremacistas de la segunda mitad del siglo XIX, que interpretaron que el tipo de pensamiento y de lengua era inherente a la raza $\mathrm{y}$, como cada raza formaba una nación, el corolario subsiguiente fue bien conocido: una raza, una lengua y una nación. De este modo, lo cultural, lo biológico y lo racial se entremezclaron en una unidad conceptual inextricable.

Por ello, no es de extrañar que los estudios que trataban de un aspecto concreto de la cultura como es la religión estuvieran entremezclados con el estudio de las lenguas. La cultura nacional, o el Volksgeist, agrupa de forma determinista diferentes aspectos como la lengua y la religión. Teología y filología siguen los mismos caminos. Tal como se recoge en este fragmento, algunos autores asumen que la lengua y la religión aparecen como un constructo consustancial a la raza:

En la ciencia de las religiones, Soury discute con Max Müller, á quien imputa el haber querido hacer una mitología comparada, en provecho exclusivo del monoteismo, faltando á la imparcialidad científica. "La historia -dice- ha cerrado la era de las grandes construcciones metafísicas de otra edad, y de las que Hegel fue el más potente y el último genio. La historia de las lenguas y de las religiones ya no se apoya en tal ó cual teoría preconcebida de una manera intuitiva, sin un examen profundo de los hechos". "La etimología, entregada entre los antiguos á todas las fantasías de la imaginación, es hoy dia una ciencia tan rigurosa como la química".

Al mismo tiempo, combate el autor la tendencia de los que quieren ver en la raza semítica un procedimiento inverso al de la raza aria, afirmando que los semitas empezaron por el monoteísmo ("Del elemento semítico en la historia" de Pompeyo Gener, Revista contemporánea, 27 de abril de 1877, páginas 481-482).

A partir de todos estos argumentos, la conclusión lógica a la que cabría llegar es que las naciones inferiores están formadas por razas inferiores que tienen un pensamiento menos desarrollado y, por tanto, una lengua y una cultura (al menos, una literatura y una religión) más básica y primitiva. A nuestro juicio, este tipo de ideología, sin duda, supondría la justificación "racional/científica" de los desastres venideros que habrían de sucederse en el siglo XX. En este sentido, es importante señalar que, según el trabajo de Hodgson (2004), el término darwinismo social no fue un término muy frecuente en las revistas de investigación hasta la etapa prebélica de la II Guerra Mundial y que, hasta entonces, el término no tuvo connotaciones negativas. De hecho, buena parte de estas ideas fueron asumidas de manera acrítica en la etapa decimonónica. A partir del presente trabajo, se puede 
observar cómo las ideas supremacistas calaron en la teoría filológica del momento y, lo que no es menos importante, dichas ideas se transmitieron con carta de cientificidad al público general mediante su publicación en la prensa hispánica. Entendemos que la publicación en la prensa supuso un instrumento que ayudó a normalizar y consolidar buena parte de las ideas supremacistas hasta la revisión que se llevó a cabo en el siglo XX, según se indica en Hodgson (2004).

Según Tordera Yllescas (2017), la figura de Ferdinand de Saussure en este contexto fue clave. En su obra póstuma, se pueden observar diferentes pasajes en los que Saussure trata de desligar el estudio filológico de la antropología y, por tanto, romper con la pretendida unidad lengua y pueblo (nación):

La lingüística tiene que diferenciarse cuidadosamente de la etnografía y de la prehistoria, donde el lenguaje no interviene más que a título de documento; tiene que distinguirse también de la antropología, que no estudia al hombre más que desde el punto de vista de la especie [...]. Gracias al método retrospectivo, el lingüista puede, pues, remontar el curso de los siglos y reconstituir lenguas habladas por determinados pueblos mucho antes de su entrada en la historia. Pero ino podrían las reconstrucciones ilustrarnos también sobre esos pueblos mismos, sobre su raza, su filiación, sus relaciones sociales, sus costumbres, sus instituciones, etc.? En suma, ¿aporta la lengua luz a la antropología, a la etnografía, a la prehistoria? Eso es lo que generalmente se cree; nosotros pensamos que hay en ello una gran parte de ilusión.

[...] primero la raza: sería un error creer que de la comunidad de lenguas se pueda deducir la consanguinidad, que una familia de lenguas recubre una familia antropológica. [...] Así la consanguinidad y la comunidad lingüística no parecen tener ninguna conexión necesaria, y es imposible deducir la una de la otra" (Saussure 1945 [1916]: 251).

A nuestro juicio, Saussure es uno de los primeros autores que observó los derroteros por lo que viraba la filología (especialmente la germánica) $\mathrm{y}$, por ello, quiso desligar la lingüística de cualquier estudio de tintes antropológicos, ya que, como se ha indicado, incluso la antropología fue víctima de los prejuicios ideológicos del momento. En este sentido, Saussure atacó unos de los pilares fundamentales del pensamiento decimonónico al dar una fuerte estocada a la supuesta unidad entre lengua, pueblo y raza. En este sentido, es reveladora la siguiente afirmación de la obra saussureana:

La unidad de raza no puede ser, por sí misma, más que un factor secundario y de ningún modo necesario de comunidad lingüística; pero existe otra unidad, infinitamente más importante, la única esencial, la que está constituida por el vínculo social: la llamaremos etnismo. Entendemos 
por etnismo una unidad basada en relaciones múltiples de religión, de civilización, de defensa común, etc., que se pueden establecer hasta entre pueblos de razas diferentes y en ausencia de todo lazo político. Entre el etnismo y la lengua es donde se establece esa relación de reciprocidad (Saussure 1945 [1916]: 252).

En este fragmento, Saussure no solo rompe con la pretendida unidad entra raza y lengua, sino que se adelanta al pensamiento antropológico moderno y considera que lo relevante no es tanto la raza (concepto creado desde la biología racista), sino el concepto de etnismo, entendido este como un constructo cultural que integra a distintas personas de acuerdo con sus creencias compartidas. Saussure considera que es el etnismo el que guarda una relación con la lengua y viceversa. Por todo ello, podemos decir que la figura de Saussure fue fundamental para poner freno a la ideología decimonónica descrita que había impregnado buena parte de las disciplinas científicas, entre ellas, la filología.

\section{CONCLUSIONES}

En este trabajo, hemos tratado de demostrar que la figura de Charles Darwin no solo fue importante epistemológicamente para el desarrollo de la biología así como para el resto de disciplinas que trataron de copiar su metodología reconstructiva o historicista/evolutiva, sino que dicha figura recoge también los prejuicios ideológicos del siglo XIX. Las distintas ciencias, cada una desde su parcela de conocimiento o saber, dieron pábulo a las tesis supremacistas hasta tal punto que se pretendió legitimar determinadas acciones que atentan contra la moral y el sentido común. Gracias a la prensa escrita, estas ideas pudieron disfrutar de una mayor difusión y, consecuentemente, de una potencial aceptación por parte del público general que no necesariamente era experto en dichas disciplinas. Por tanto, se puede observar una constante retroalimentación entre los prejuicios populares y los prejuicios de la ciencia especializada. Las consecuencias que tuvieron estas ideas en el siglo XX son bien conocidas y, sin duda alguna, fueron abominables.

La filología, mal que nos pese, no fue una excepción, sino que también contribuyó a este clima ideológico. En consecuencia, toda historia de la filología que quiera abordar no solo los aspectos internos de la disciplina, sino también los condicionantes sociohistóricos del momento debe tener en consideración estos hechos. A nuestro juicio, dicho conocimiento nos hace 
valorar doblemente la contribución que realizó Ferdinand de Saussure a nuestra disciplina. No solo hizo más "científica" a la lingüística, sino que la hizo, sobre todo, más sensata.

\section{REFERENCIAS BIBLIOGRÁFICAS}

Alonso-Cortés, Ángel. 2002. Lingüística. Madrid: Cátedra.

Arens, Hans. 1976 [1969]. La Lingüistica. Madrid: Gredos.

Armelagos, George J., y Goodman, Alan H. 1998. Race, racism, and anthropology. En Aland H. Goodman y Thomas L. Leatherman (ed.). Building a new biocultural synthesis: Political-economic perspectives on human biology. Michigan: University of Michigan, 359-377.

Arriola, JonAthan. 2009. Una aproximación a la obra de Johann Gottfried Herder ¿Qué es la nación? Letras internacionales 82 (3. Disponible en https://revistas.ort.edu.uy/letrasinternacionales/article/view/1708.

BaKer, Lee D. 1998. From savage to Negro: Anthropology and the construction of race, 1896-1954. University of California Press.

Ballantyne, Margaret A. 1990. Índice de la Revista de España bajo la dirección de Galdós. Hispania 73 (2) 1990: 332-344.

Barkan, ElazAr. 1992. The Retreat of Scientific Racism: Changing Concepts of Race in Britain and the United States between the World Wars. Nueva York: Cambridge University Press.

Belloch, Amparo, Galdón, María José y Pascual-Vera, Belén (2020). En Amparo Belloch, Bonifacio Sandín y Francisco Ramos (ed.). Manual de psicopatología. Madrid: McGrawHill. 3-34. $3^{\text {a }}$ edición.

Bender, Daniel E. 2009. American Abyss: Savagery and Civilization in the Age of Industry. Ithaca: Cornell University Press.

Berlin, Isaiah. 2009. Return of the Volksgeist. New Perspectives Quarterly 26: 29-39.

Bernal, Martín. 1993 [1987]. Atenea negra. Las raíces afroasiáticas de la civilización clásica. Vol. I. Madrid: Crítica.

Blikstein, IZIDORO. 1992. Indo-europeu, lingüística e... racismo, Revista USP (14. Disponible en 104-110. https://doi.org/10.11606/issn.2316-9036.v0i14p104-110.

Burgos, Juan Manuel. 2014. Historia de la Psicología. Madrid: Ediciones Palabra.

CABrera-Guillén, Amadeo Arturo. 2019. Morfología craneal y facial. Estigmas racistas según el pensamiento del siglo XIX. Revista Minerva 2 (2): 9-17.

Chiaretto, Marcelo. 2002. Ser crivado de raças, culturas e realidades: o Volksgeist no Brasil. Em Tese 5, pp. 63-70.

COSERIU, Eugen. 1986. Introducción a la lingüistica. Madrid: Gredos.

Černý, Jiri. 1998. Historia de la linguistica. Cáceres: Servicio de Publicaciones de la Universidad de Extremadura..

DARWIn, ChARLES. 1972 [1871]. El origen del hombre. Madrid: EDAF.

EHRENREICH, ERIC. 2007. The Nazi ancestral proof: genealogy, racial science, and the final solution. Bloomington: Indiana University Press.

Ferrater Mora, José. 1979. Diccionario de filosofia. Madrid: Alianza Editorial. 
Foley, William A. y Robert D. JR. Van Valin. 1984. Functional syntax and universal grammar. Nueva York y Melbourne: Cambridge University Press.

Gallardo Paúls, Beatriz. 2000. Evolución de lenguas y tipología. Valencia: Tirant lo Blanch.

Gondra, José María. 2011. Historia de la Psicología. Introducción al pensamiento psicológico moderno. Volumen I: Nacimiento de la Psicología Científica. Madrid: Síntesis.

Harris, Marvin. 2007 [1968]. El desarrollo de la teoría antropológica. Madrid: Siglo XXI.

Hodgson, Geoffrey M. 2004. Social Darwinism in Anglophone academic journals: A contribution to the history of the term. Journal of Historical Sociology 17 (4): 428-463.

Hualde, José Ignacio, Olarrea, Antxon, Escobar, Anna María, Travis, Catherine E., y SANZ, CRISTINA. 2020. Introducción a la lingüistica hispánica. Cambridge: Cambridge University Press.

Juan Lovera, Carmen. 1975. Don Juan Valera ante la restauración. Boletín del Instituto de Estudios Giennenses 83: 27-64.

KeVles, Daniel J. 1986. In the Name of Eugenics: Genetics and the Uses of Human Heredity. Cambridge: Harvard University Press.

Koerner, E. F. Konrad. 1973. Ferdinand de Saussure. Origin and Development of his Linguistic Thought in Western Studies of Languages. Berlín: Springer.

KüHL, STEFAn. 1994. The Nazi Connection: Eugenics, American Racism, and German National Socialism. Nueva York: Oxford University Press.

Lombardo, Paul A. 2011. A Century of Eugenics in America: From the Indiana Experiment to the Human Genome Era. Indiana: Indiana University Press.

Leathy, Thomas Hardy. 1998. Historia de la Psicología. Principales corrientes en el pensamiento psicológico. Madrid: Prentice Hall Iberia S.L.

Linton, Ralph. 2000 [1936]. Estudio del hombre. México: Fondo de Cultura Económica.

Malmberg, Bertil. 1985 [1982]. Introducción a la lingüística. Madrid: Cátedra.

Marcos Marín, Francisco. 1994. Introducción a la lingüística: historia y modelos. Madrid: Síntesis.

Martín Vide, Carlos. 1996. Elementos de lingüística. Barcelona: Octaedro.

Mineau, ANDRÉ. 2004. Operation Barbarossa: Ideology and Ethics against Human Dignity. Londres: Rodopi.

Moreno Cabrera, Juan Carlos. 1997. Introducción a la lingüística, enfoque tipológico y universalista. Madrid: Síntesis.

2000. Curso universitario de lingüistica general. Tomo I: Teoría de la gramática y sintaxis general. Madrid: Síntesis.

Newmeyer, Frederick. 1990 [1988]. Panorama de la Lingüistica moderna. I Teoría lingüística y aplicaciones. Madrid: Visor.

Olmedo Montes, Margarita. 2005. La influencia de la herencia y el ambiente en la diversidad psicológica humana. En Ángeles Sánchez-Elvira Paniagua (ed.). Introducción al estudio de las diferencias individuales. Madrid: Sanz y Torrens, pp. 505-546.

Olmedo Montes, Margarita y Ángeles Sánchez-Elvira Paniagua. 2005. Desarrollo histórico del estudio de las diferencias individuales I: etapa precientífica y establecimiento de la Psicología diferencial como disciplina científica. En Ángeles Sánchez-Elvira Paniagua (ed.). Introducción al estudio de las diferencias individuales. Madrid: Sanz y Torrens, pp. 3-51.

Palti, Elías JosÉ. 1997. La metáfora de la vida. Herder, su filosofía de la historia, y la historia de un desencuentro. Revista de Filosofía Diánoia 43: 95-124.

Pereira Poza, ANTONio. 2000. Charles Bell: Naturalismo teológico y frenología. Implicaciones sociales. Asceplio 52 (1): 185-192. 
Poliakov, Leon. 1974. Aryan Myth: A History of Racist and Nationalist Ideas in Europe. Nueva York: Basic Books.

Ramaswamy, Sumathi. 2004. The Lost Land of Lemuria Fabulous Geographies, Catastrophic Histories. Berkeley, Los Ángeles y Londres: University of California Press.

Richards, Graham. 1997. 'Race', Racism and Psychology. Londres y Nueva York: Routledge.

Robins, Robert H. 2000 [1967]. Breve historia de la Lingüistica. Madrid: Síntesis.

SÁNCHEZ Arteaga, JuAnMa. 2006. Las Teorías biológicas sobre el origen de las razas humanas (1859-1900): elementos para una crítica antropológica de la racionalidad tecnocientífica. Tesis Doctoral. Madrid: Universidad Autónoma de Madrid.

Saussure, Ferdinand DE. 1945 [1916]. Curso de lingüistica general. Buenos Aires: Editorial Losada.

Smith, Justin E. H. 2015. Nature, Human Nature, and Human Difference. Princeton: Princeton University Press.

Stocking, George W. 1982 [1968]. Race, culture, and evolution: Essays in the history of anthropology. Chicago: University of Chicago Press.

Thomas, Alexander y Samuell Sillen. 1972. Racism and Psychiatry. Nueva York: Carol Publishing Group.

Tordera Yllescas, Juan Carlos. 2017. Cien años después del Curso de lingüística general: una revisión a la obra de Ferdinand de Saussure. Onomázein 38, pp. 213-232.

Tortosa, Francisco y Cristina Civera. 2006. Historia de la Psicología. Madrid: McGrawHill Interamericana de España S.L.

Twine, Richard. 2002. Physiognomy, Phrenology and the Temporality of the Body. Body and Society 8 (1): 67-88.

Tucker, William H. 1994. The Science and Politics of Racial Research. Champaign: University of Illinois Press.

Velasco Maillo, Honorio M. 2007. Hablar y pensar. Temas de Antropología Lingüística y Antropología Cognitiva. Madrid: UNED.

Villar, Francisco. 1996. Los indoeuropeos y los orígenes de Europa. $2^{\text {a }}$ Edición. Madrid: Gredos.

Vinatea Serrano, Eduardo. 2008. Lecciones de Antropología social y cultural. Madrid: Dyckinson. 2009. Lecturas de Antropología social y cultural. Madrid: Dyckinson. 